\title{
Bilgi Toplumu, Sayısal Uçurum ve Kronik Bilgi Yoksulluğu
}

\author{
Information Society, Digital Gap and Chronic Information Poverty
}

\section{Güler Demir*}

Developments in post-industrial societies shaped by the factors of globalization and the speed and diversity of information and communication technologies have been subjects to various conceptualizations along with different approaches and paradigms. The concepts of information, information society, information age, digital divide, information poverty and chronic information poverty are the main examples of these tendencies. The editorial of this issue aims to provide a general and conceptual framework for the mentioned issues.

Değerli Okurlarımız,

İçinde bulunduğumuz yüzyılda, "bilgi", "bilgi toplumu", "bilgi çağı", "sayısal uçurum" ve "bilgi yoksulluğu" gibi kavramları sıklıkla duymaktayız. Öte yandan, hızla gelişen ve çeşitlenen teknolojiler ile gittikçe küreselleşen, küçülen dünya, beraberinde pek çok kolaylığ getirdiği gibi, çok çeşitli sorunları da açığa çıkarmıştır. Sayısal uçurum, bilgi yoksulluğu ve özellikle bilgi yoksulluğunun kronik biçimi, bunlar arasında en fazla öne çıkan sorunlardır. Dolayısıyla, Türk Kütüphaneciliği'nin bu sayısına ilişkin editoryal yazıda, ana hatları ile de olsa anılan konulara kısaca değinmenin yararlı olacağı düşünülmüştür.

Henüz 1964 yılında McLuhan'ın çalışmalarındaki küreselleşme ve teknolojinin dünyadaki dengeleri değiștireceği öngörüsü; Bell'in $(1973,1976)$ sanayi sonrası toplumlarda gerek teknolojik gerekse toplumsal yapılardaki değişime ilişkin vurguları, literatürde önemli tartışma ve çalışmalara ilham olmuştur. Daha yakın tarihlerde, pek çok araştırmacı, çeşitli paradigmaları ile toplumların gelişen teknoloji ile küreselleşme sonucu karşılaşacağı sorunlara; yeni toplumsal ilişkiler ile yapılanmalara ilişkin görüşlerini sunmuştur. "Üçüncü dalga" paradigması ile Toffler (1981); "teknopoli" kavramlaştırması ile Postman (1993) ve "enformasyon bombası" nitelemesi ile Paul Virilio (2003) bunlara örnektir. Beck (2019) ve Castells (2009) gibi birçok yazar da, teknolojinin yan etkileri olan çevre ve hava kirliliklerine, küresel ısınma ile kimyasal tehditlere ve tüm ilişkilerin ağlar üzerine taşındığı yeni çağın değişen dengelerine dikkati çekmiştir. Hemen hepsinin üzerinde uzlaştığ 1 durum, bilginin değişen form ve yapısı ile artan gücüdür. $\mathrm{Bu}$ da doğal olarak ekonomik, politik, sosyal, toplumsal, kültürel, eğitsel ve hangi alanda olursa olsun, güç dengelerinin bilgi sahibi olanların lehine geliştiği ve gelişeceği anlamına gelmektedir. Karvonen'in bir çalışmasında geçen ifadeler de bunu kanıtlamaktadır. Karvonen'e (2001, s. 200-201) göre, toplumlarda bilgi ve

\footnotetext{
* Türk Kütüphaneciliği Editörler Kurulu Üyesi. Kastamonu Üniversitesi, Bilgi ve Belge Yönetimi Bölümü, Kastamonu, Türkiye. E-posta: gulerdemir2009@gmail.com

Member of Turkish Librarianship Editorial Board. Kastamonu University, Department of Information and Records Management, Kastamonu,Turkey.E-mail: gulerdemir2009@gmail.com
}

Geliş Tarihi - Received: 29.06.2021

Kabul Tarihi - Accepted: 29.06.2021

Yayımlanma Tarihi - Published: 30.06.2021 
bilginin rolünün güçlenmesi, eşitsizliğin kaynaklarını yeniden yapılandıracağından, toplumsal eşitsizlik kavramı ve toplumsal ilişkiler değişecektir. Sosyal güç, giderek bilgi üzerindeki güce bağımlı hale gelecektir. İletişim ve bilgi araçlarının dönüşümü ile beraber okuryazarlığın önemi ve boyutları da değişime uğrayacaktır. Çeşitli sosyal grupların birbirlerine göre konumları ve önemleri farklı anlamlar kazanacak ve belirli bir toplumdaki iletişime dâhil olanlar ile olmayanlar arasındaki uçurum büyüyecektir. Uluslar veya bölgeler arasındaki merkez ve çevre ilişkileri de sarsılabilecek ve varsa küresel iletişimden kopuk toplumlar veya bölgelerin, daha önce zaten var olan dezavantajları daha da büyüyecektir. Küresel topluluğa üyelikte iletişim ve ilişkilerin toplumun seçkinleriyle sınırlı olması da toplumsal uçurumu yaratacak ayrı bir tehdit halini alacaktır.

Tam da bu noktada, sıklıkla literatüre konu olan "sayısal uçurum" ve "bilgi yoksulluğu" gibi kavramlar akla gelmektedir. 1990'ların ortalarında yayılmaya başlayan sayısal uçurum kavramı, yeni bilgi teknolojisi biçimlerine erişimi olanlarla olmayanları ayıran boşluğu ifade etmektedir. Bilgi yoksulluğu ise bilgilere erişimi engelleyen, yanlış yönlendiren bilgi kıtlığ1 veya aşırı bilgi yüklenme koşullarıyla karakterize edilen karmaşık bir sosyal fenomen olarak tanımlanmaktadır (Srinuan ve Bohlin, 2011; Community, Equity, Data \& Information Lab., 2021). Samek'e (2007, s. xi) göre, bilgi toplumu, yoksulluğun yanı sıra yeni bir zenginlik türü, yeni bölünmeler ve farklılıklar ortaya çıkarmış; çağdaş sosyal dışlanma ve cehalet biçimlerini icat etmiştir. Bilginin önemli kısmını elinde tutan, diğerlerini kontrol edenler ile en değerli bilgilere (tıp, biyoloji, mühendislik, tarım, genetik, bilgisayar ve telekomünikasyon gibi) fiyat koyarak para hazinelerini büyüten çok uluslu şirketler karşısında, dünyanın çok önemli bir bölümü hala toplumsal gelişme ve ilerlemenin gölgesinde kalmaktadır.

Gelişmiş ülkelerde de yaşanmasına karşın daha çok gelişmekte olan ülkeleri etkileyen bilgi yoksulluğunun arka planında, eğitsel, bilimsel ve teknolojik altyapı, politik, sosyal ve kültürel sistemler, demokratik nitelik ve insani koşullar gibi çeşitli karmaşık faktörler yer alır. İyi bir eğitim altyapısı ile sistemine sahip, demokratik, eşitlikçi ve şeffaf toplumlar için bilgiye eşit erişim çok önemlidir. Bu yapının temel ölçütü, kişisel olsun ya da olmasın hiç kimsenin bilgiye erişiminin ve/veya bilgi paylaşımının engellenmemesidir (Demir, 2020).

Chatman $(1987,1991,1996)$ tarafından dile getirilen kronik bilgi yoksulluğu (chronic information poverty) ya da aşırı bilgi yoksulluğu (extreme information poverty), bilgi yoksulluğunun maksimum düzeyini ifade eden bir kavramdır. Chatman, bilgi davranışları ile kişinin içinde bulunduğu sosyal sınıf ve bu sınıfa ilişkin normlar arasında önemli bir ilişki olduğu görüşündedir. Kişi için bilginin referans kaynağı, Chatman'in kuramında geçen ifadesi ile ait olduğu "küçük dünya"sıyla (small world) sınırlı kalmaktadır. Bilgi yoksulluğu kavramına, bilgi sosyolojisi ve etnografya gibi diğer disiplinlerden yaklaşan Chatman (1996, s. 194), bu kavramın, bilgiye dâhil olanları (information insiders) ve bilginin dişında kalanları (information outsiders) kapsayan geniş bir çerçevesi olduğuna işaret etmektedir. Paradoksal olarak yazar, iki grubun da bilgi arama ve paylaşma davranışlarında kendilerinin yarattığı çeşitli engellere vurgu yapar. Bilgiye dâhil olanlar, statüleri nedeniyle, kendileri tarafindan oluşturulmayan bilgi kaynaklarını kabul etmeyerek bilgi yoksulluğunu pekiştirmektedir. Dolayısıyla bilgiye dâhil olanların dünyasında, bilginin dışında kalanların bilgileri ve önerilerine yer olmadığı gibi neyin önemli olup neyin olmadığını kendi dünyalarının belirlediği normlar ve adetler tanımlamaktadır. Bilgiye dâhil olanların olmayanlara ilişkin geliştirdikleri 
bir tür önyargı, Chatman'in (1996, s. 194) görüşüne göre, kendi izole, küçük dünyalarının yalnız kendileri gibi dâhil olanlar tarafindan anlaşılabileceği biçimindedir. $\mathrm{Bu}$, aynı zamanda güvende olma ve korunma kaygısından kaynaklanmaktadır. Chatman (1987, 1991, 1999), örneğin, düşük gelirli çalışanların, yoksul işçilerin, iş arayanların ve yüksek güvenlikli bir kadın cezaevindeki mahkûmların, içinde bulundukları sosyal koşulların etki ettiği marjinalleşmenin, bilgi yoksulluğu bağlamında belirleyiciliğine dikkati çekmiştir. Kuşkusuz, insanların bilgi yoksulluğunu nasıl deneyimledikleri değişmektedir ancak genellikle insanlar bilgi yoksulu olduklarında, kendi dünya görüşlerine hitap eden kıt bilgi kaynakları ile yetinmekte ve dışarıdan gelen bilgilere şüpheyle bakmaktadır. Özellikle, yoksul insanların başarılı olma konusunda güvensizlikleri ve daha düşük beklentiye sahip olmaları, yeni firsatlara ilişkin girişimlerini kısıtlamakta, bu da bilgi yoksulluğunu daha yüksek düzeye çıkarmaktadır (Chatman, 1991, s. 438).

Bilgi merkezlerinin bilgi yoksulluğunu giderecek katalizör işlevleri olduğuna inanılmaktaysa, bilgi yoksulluğu ve özellikle de kronik bilgi yoksulluğu, hem bilim insanları ve akademisyenler hem de uygulamacılar tarafindan tüm boyutları ile ele alınması gereken önemli bir sorundur.

Değerli Okurlarımız,

Türk Kütüphaneciliği'nin bu sayısının kapsamına ilişkin bilgi vermeden önce, 2021 yılında hangi gelişmelerin gerçekleştiği konusunda kısaca hatırlatmada bulunmak yararlı olacaktır. Dergimizin daha önceki sayısında da açıklandığı gibi, 2021 yılında Yönetim Belgesi güncellenmiştir. Bunun dışında, Türk Kütüphaneciliği'ne gönderilecek makalelerin şablonu da yeniden gözden geçirilerek geliştirilmiş ve İngilizceye çevrilmiştir. Şablonda belirtilen önemli bir değişiklik, bu sayı ile birlikte APA 7 stilinin uygulanmasına ilişkin alınan karardır. Amerikan Psikoloji Derneği (APA), Ekim 2019'da, APA Publication Manual'ın 7. basımını tanıtmıştır. 2009'da yayınlanan APA 6'nın yayınlanmasından bu yana değişen pek çok şey APA 7 ile temsil edilmektedir. Özellikle, çevrim içi materyallerden alıntı yapmanın daha yaygın hale gelmesi, kapsayıcı ve önyargısız dil kullanımının giderek daha önemli sayılması ve araştırmacılar ile öğrenciler tarafından kullanılan teknolojilerin değişmesi, APA 7'nin geliştirilmesine etki eden etmenler arasındadır. 7. basım, daha iyi ve daha kapsamlı yönergeler sağlayarak bu değişiklikleri ele almaktadır (Streefkerk, 2020).

Türk Kütüphaneciliği için alınan bir diğer önemli karar, ULAKBİM TR ölçütlerine uygun olarak 2021 yılından itibaren Etik Kurul onayı gerektiren çalışmaların yüklenmesinde makale dosyası ile birlikte Etik Kurul belgesinin yüklenmesi gerekliliğidir. Anket, mülakat, odak grup çalışması, gözlem, deney, görüşme teknikleri kullanılarak katılımcılardan veri toplanmasını gerektiren nitel ya da nicel yaklaşımlarla yürütülen her türden araştırma; insan ve hayvanların (materyal/veriler dâhil) deneysel ya da diğer bilimsel amaçlarla kullanılması; insanlar üzerinde yapılan klinik araştırmalar; hayvanlar üzerinde yapılan araştırmalar ve kişisel verilerin korunması kanunu gereğince retrospektif çalışmalar, Etik Kurul izni gerektiren araştırmalardır.

Türk Kütüphaneciliği'nin bu sayısında "Hakemli Yazılar" bölümünde yayımlanan çalışmalar arasında yer alan;

“Birinci Dünya Savaşı'nda Amerikan Kütüphane Derneği'nin ABD Ordusuna Yönelik Hazırladığı Propaganda Posterleri Üzerine İnceleme” başlıklı makale, Amerikan Kütüphane Derneğinin (American Library Association/ALA) Birinci Dünya Savaşı'nda yürüttüğü kitap 
seferberliğini konu almaktadır. Çalışmadan elde edilen bulgular, posterlerin verimli biçimde kullanıldığına ve kitap okumanın ABD askerleri için iyi bir boş zaman aktivitesi olduğuna işaret etmektedir. Alanımızda köklü bir tarihe sahip olan ve aynı zamanda toplumsal ve politik sorunlara ilişkin duyarllık anlamında kütüphanelerin aktif konumunu da teşvik eden ALA'nın bu kampanyasını konu alan çalışma, benzer çalışmaların sınırlılığı nedeni ile literatür için önemli bir katkıdır.

"Çin Halk Cumhuriyeti'nde Sovyet Revizyonizmi'ne Karşı Kitapların Propaganda Amaçlı Kullanımı" başlıklı çalışmada, Çin Halk Cumhuriyeti (ÇHC) ve Sovyetler Birliği arasında gelişen diplomatik ayrılığı ifade eden, Sovyet Revizyonizmi olarak adlandırılan ve Kruşçev Çözülmesi olarak bilinen dönemde, kitap propagandaları konusu ele alınmaktadır. Anılan dönemde, ÇHC tarafindan Marksizm'in temelinden uzaklaştığı düşünülen Sovyet Revizyonizmi'ne karş̧ yöneltilen propagandalarda, kapitalizme karş̧, Marksist-Leninist temal1, Mao'nun düşüncelerini yansıtan kitapların ön plana çıkarıldığı posterler kullanılmış̧ır. Çalışmanın sonucu, ÇHC'nin Sovyetler Birliği'ne karşı başlattı̆̆ ideolojik mücadelede kullandığ1 Marksist-Leninist ideolojiyi yaygınlaştıran kitapların etkin rolünü ortaya çıkarmaktadır. Bu araştırma da oldukça özgün ve literatüre katkı sunan bir çalışmadır.

"Karolenj Rönesansı Bağlamında Kütüphaneler, Manastırlar ve Karolenj El Yazmaları" başlıklı diğer bir çalışmanın konusu, 16. yüzyılda Avrupa'yı etkisi altına alan Karolenj döneminin entelektüel boyutu içinde manastır kütüphanelerinin yeridir. Araştırma kapsamında ayrıca Kral Şarlman dönemi entelektüel anlayışının Kilise ile olan bağlantısı irdelenmiş ve Klasik dönem el yazmalarının Karolenj manastır ve saray kütüphanelerinde çoğaltılmasının ve Karolenj Rönesansı açısından öneminin altı çizilmiştir. Çalışmanın sonucunda, kilise-devlet ilişkisinin dini ve entelektüel etkilerine vurgu yapılmış; manastırlar bünyesinde kitap çoğaltılmasını hızlandırma ve zenginleştirme açısından kilise ile olan ilişkilerin doğrudan etkili olduğu kanısına varılmıştır. Ayrıca, Karolenj dönemiyle birlikte zaman içinde ortaya çıkan el yazması ekollerinde değişiklik görüldüğü sonucuna da ulaşılmıştır. Bu araştırma, ulusal literatürde Karolenj Rönesansı ve entelektüel alana nüfuzu ile ilgilenen sınırlı sayıda çalışma bulunması ve bu bağlamda manastır ya da katedral gibi dini kurumlar bünyesindeki kütüphaneleri odak alan çalş̧maların eksikliği nedeni ile literatüre önemli katkısı olan bir çalı̧̧madır.

2020 yılında hazırlanmış olan doktora tezine dayanan "Akademisyenlerin Akademik Sosyal Ağlara Yönelik Tutumları: Ankara Üniversitesi Örneği” başlıklı çalışmada, Ankara Üniversitesi akademisyenlerinin akademik sosyal ağlara ilişkin tutumlarının ve akademik sosyal ağlardan ne ölçüde yararlandıklarının ortaya çıkarılması amaçlanmıştır. Çalışmadan elde edilen sonuç, Ankara Üniversitesi akademisyenlerinin çoğunluğunun akademik sosyal ağları kullandığı ve bu bağlamda farkındalığının olduğu biçimindedir. Sosyal ağların kullanımında akademisyenlerin yaşadıkları sorunlar ise daha çok düzenli kullanım sağlamada, geri bildirimleri takip etmede ve yayın isteklerini karşılamada zorlanmalarıdır. Sosyal ağların gittikçe daha fazla bilimsel paylaşımlara zemin sunması ve kurumsallaşması nedeni ile güncel ve önemli bir temaya odaklanılmıştır. Uluslararası literatürde konu bağlamında pek çok çalışma bulunmasına karşın yerel literatürde sınırlı sayıda çalışma olması nedeni ile bu araştırma, özgün ve yerel literatüre katkı sunan niteliktedir.

"Forecasting the Number of Visitors of the Museums and Ruins by Using Time Series Analysis: The Case of Turkey" başlıklı diğer bir makalede, Türkiye'de 2037 yılına kadar müze 
ve ören yerlerini ziyaret edeceklerin sayısını tahmin etmek amaçlanmıştır. Çalışma sonunda ortaya çıkarılan bulgular, zaman serilerinin Türkiye'deki müze ve ören yerlerini ziyaret edenlerin sayısındaki artış eğilimine işaret eden oldukça kullanışlı tahminler içerdiğine işaret etmektedir. Bu çalışmanın, içeriklerini dijitalleştirmek isteyen müzeler ve ören yerleri için ışık tutacağı ve aynı zamanda fiziksel ve dijital kullanıcılarla ilgili konuların karşılaştırıldığı çalışmalara da olanak sağlayacağı düşünülmektedir.

"5-6 Yaş Resimli Çocuk Kitaplarındaki Resim ve İçerik Ögelerinin MEB Okul Öncesi Eğitim Programı Sosyal-Duygusal Alan Kazanım ve Göstergeler Açısından İncelenmesi” başlıklı makale, resimli çocuk kitaplarının çocuğun duygusal, sosyal ve entelektüel gelişimine katkısını göstermesi bağlamında dikkati çeken bir çalışmadır. Çalışmada, 5-6 yaş okul öncesi dönem resimli çocuk kitaplarındaki resim ve içerik ögelerinin MEB 2013 Okul Öncesi Eğitim Programı sosyal-duygusal alan kazanım ve göstergeleri açısından incelenmesi amaçlanmıştır. Makalenin ortaya çıkardığı sonuç, okul öncesi dönem çocuklarına yönelik resimli çocuk kitaplarında sıklıkla yer verilen kazanımlara karşın hiç yer verilmeyen kazanımların varlığını ortaya koymakta ve bu anlamda boşluğun nitelikli kitaplarla doldurulması gerektiği önerisine yer verilmektedir.

“Okuma Üzerine Sanat Temelli Boylamsal Bir Araştırma: İlkokul Öğrencileri Okurken Nasıl Hissediyor?" başlıklı çalışmanın amacı, ilkokul öğrencilerinin okurken nasıl hissettiklerinin belirlenmesi ve aradan iki y1l geçtikten sonra bu duygulardaki değişimin ve gelişimin ortaya konulmasıdır. Bursa'ya bağlı İnegöl ilçe merkezindeki bir ilkokulda öğrenim gören 126 öğrencinin çalışma grubunu oluşturduğu araştırmada, "Kitap okurken neler hissettiğini veya nasıl hissettiğini bir resim çizerek gösterir misin?” açı uçlu sorusuna yönelik öğrencilerin ikinci ve dördüncü sınıfta yapmış olduğu çizimler karşılaştırmalı olarak değerlendirilmiştir. Araştırma verileri 2016-2017 ve 2018-2019 eğitim öğretim yıllarının bahar yarıyılında toplanmıştır. Çalışmanın sonuçları, öğrencilerin çoğunun -hem ikinci hem dördüncü sınıf düzeylerinde- okuma süreçlerinde olumlu duygular içinde olduğunu ve sınıf düzeyi ilerledikçe okumaya dair olumlu duygularının daha da çoğaldığını ortaya çıkarmıştır. İlkokul öğrencilerinin okurken yaşadıkları duyguların çizimler aracılığıyla ortaya konulduğu çalışmalara rastlanmaması nedeni ile bu çalışma oldukça özgün ve literatüre katkı sağlayan niteliktedir.

“Görüşler” ve “Okuyucu Mektupları” bölümünde yayımlanan;

"Çeviri Yazı, Romanizasyon ve Kütüphanecilik” başlıklı çalışmada ise, dil, metin, harfler arasında aktarım yapılmasını sağlayan sistem örnekleri olarak çeviri yazı ve romanizasyon konusu ele alınmıştır. Çalışmanın amacı, bir dilin alfabesinde yer alan harflerin başka bir dilin alfabesine dönüştürülmesi ve/ya da bir eserin ya da metnin başka bir dile aktarılması süreçlerinde karşılaşılan sorunları irdelemektir. Kütüphanecilik açısından ele alınan kavramlar ve bu çerçevede yaşanan sorunlar, kataloglama ve kullanıcı özelinde ele alınmıştır. Sorunlara çözüm olarak, gelişen bilgi teknolojisinden yararlanılması, kullanılan formatlara farklı dillerin karakterlerinin entegre edilmesi ile karakter seçeneklerinin çoğaltılması gibi öneriler sunulmaktadır.

"Batman Şehit Şenay Aybüke Yalçın İl Halk Kütüphanesi” başlıklı, görsellerle de zenginleştirilen bir diğer araştırmada, yeniden yapılandırılan Batman İl Halk Kütüphanesi ve bağlı kütüphanelerinin hakkında kapsamlı bilgiler verilmektedir. Çalışmada, söz konusu 
kütüphanelerin, engellilere yönelik olanlar da dâhil hizmetleri, bölümleri, koleksiyonları, teknolojileri, cihazları vb. tanıtılmaktadır. 21. yüzyılın becerileri arasında önemli yeri olan girişimcilik, yenilikçilik, yaratıcılık ve kendin yap (Do it yourself/DIY) felsefesini temsil etmesi anlamında, robot, araba, telefon, bilgisayar, televizyon, banka kart1, mikrodalga vb. yapımı için zemin sunan teknoloji ve yapım atölyeleri, gelecek vadeden hizmetler sunmaktadır. Teknoloji Atölyesi'nde, robotik kodlama ve programlama dillerini uygulamaya geçiren eğitim programlarının hazırlanması da planlanmaktadır.

"Biblioburro: Kolombiya'da Eşekli Kütüphane Girişimi”" başlıklı çalışmada, Kolombiya'nın La Gloria isimli kırsal bölgesinde İspanyolca öğretmeni olan Luis Soriano tarafından 1997 yılında başlatılan eşekli kütüphane girişiminin anlatılması amaçlanmıştır. Çalışmada varılan sonuç, projesi ile sosyal medyaya da (Facebook) konu olan Soriano'nun, çocukların kişisel ve kültürel gelişimlerine katkıda bulunmak bağlamında dünyaya örnek olduğu biçimindedir. Ayrıca bu girişim ününü Kolombiya dışında da duyurmuş, CNN ve New York Times'ın ana haberlerine konu olmuştur.

Türk Kütüphaneciliği'nin bu sayısında, nitelikli çalışmalarla siz okurlarımıza ulaşırken bir taraftan da buruk ve hüzünlüyüz. 11 Mart 2020 tarihinde Dünya Sağlık Örgütü tarafından küresel salgın olarak ilan edilen COVID-19 pandemisinin aramızdan aldığı değerli isimlerin yarattığı acı, onların ardından yazılanlar ile yüreklerimize işliyor. Koronavirüs salgını ile yitirdiklerimizin arasında, "olmadı", "çok erkendi” dediğimiz iki güzel insan yer alıyor: 18 Nisan 2021 tarihinde vefat eden Hazine Bakanlığı Kütüphanesinde çalışan değerli meslektaşımız Neslihan Güler Selçuk ve 19 Kasım 2020 tarihinde hayatını kaybeden bir diğer değerli meslektaşımız Burdur Mehmet Akif Ersoy Kütüphanesi Kütüphane ve Dokümantasyon Daire Başkanı İsmail Kutluay. Bu iki güzel insanın ardından “Okuyucu Mektupları” bölümünde yazılanlar, duygu yoğun, hüzünlendiren, zaman zaman da acı acı gülümseten, geçmişteki anılara götüren ifadelerle dolu.

Bizlere yaşamın geçiciliğini unutturan ölümler, hele bir de aniden geliverdiklerinde, o ilk anlarda, duygularımız sözcüklere sığmayıp taşıyor; dilsizleşiyoruz. Sonrasında zihnimizde yitirilene ait fotoğraf kareleri öylesine canlı dolaşıyorlar ki, ölüm kavramının kendisi dahi inanılmaz bir fenomene dönüşüyor. Kısacası, her ölüm zor, her ölüm erken! Öte yandan, bu geçici hayattan, herkes ardında güzellikleri bırakıp gitmiyor. Yazılanların da açık seçik gösterdiği gibi, Neslihan Güler Selçuk ve İsmail Kutluay, pek çok güzelliği bırakarak gidenlerin arasındalar; mekânları cennet olsun ve huzurla uyusunlar.

Değerli Okurlarımız,

Türk Kütüphaneciliği Editörler Kurulu'na 11 Ocak 2021 tarihinde dâhil oldum. Zihnimde "Başarabilir miyim?", "Yapabilir miyim?” gibi sorular ve tedirginlikler vardı. Hem çok değerli Türk Kütüphaneciliği Sorumlu Yazı İşleri Müdürü Mehmet Tayfun Gülle'nin hem de sevgili editör ve editör yardımcısı arkadaşlarımın süreçlere uyum sağlamam konusunda bana çok fazla destekleri oldu. Buradan kendilerine çok teşekkür ediyorum. Sizlerle paylaşmak istediğim bir düşüncem de şu: Sürece dâhil olduktan sonra, Türk Kütüphaneciliği’ne gönderilen çalışmaların gerek editoryal düzenlemeleri sırasında gerekse bilimsel süreçlere hazırlıklarında tahminlerimin çok ötesinde emeklerin verildiğini gördüm. Aynı zamanda, ekip ruhu ile kolektif, disiplinli çalışmanın, samimiyetin ve paylaşımın değerini bir kez daha anladım. Alan editörü 
ve İngilizce redaksiyon editörü olarak sorumlu olduğum bu değerli ekipte alanımıza hizmet etmekten çok mutluyum. Yeni sayımızda buluşmak üzere...

Saygilarımızla.

\section{Kaynakça}

Beck, U. (2019). Risk toplumu: Başka bir modernliğe doğru (K. Özdoğan ve B. Doğan, Çev.). İthaki.

Bell, D. (1973). The coming of post-industrial society. Basic Books, Inc. Publishers.

Bell, D. (1976). The coming of the post-industrial society, The Educational Forum, 40(4), 574-579.

Castells, M. (2009). Communication power. Oxford University Press.

Chatman, E. A. (1999). A theory of life in the round. Journal of the American Society for Information Science, 50(3), 207-217.

Chatman, E. A. (1991). Life in a small world: Applicability of gratification theory to informationseeking behavior. Journal of the American Society for Information Science, 42(6), 438-449.

Chatman, E. A. (1996). The impoverished life-world of outsiders. Journal of the American Society for Information Science, 47(3), 193-206.

Chatman, E. A. (1987). The information world of low-skilled workers. Library and Information Science Research, 9(4), 265-683.

Community, Equity, Data \& Information Lab. (2021). Deconstructing information poverty study (DIPS). https://cedi.unc.edu/dips/

Demir, G. (2020). Democratic and educational background of information poverty: The case of Turkey. Journal of Contemporary Issues in Education, 15(1), 65-80.

Karvonen, E. (Yay. Haz.) (2001). Informational societies: Understanding the third industrial revolution. Tampere University Press.

McLuhan, M. (1964). Understanding media: The extensions of man. McGraw Hill.

Postman, N. (1993). Technopoly: The surrender of culture to technology. Vintage Books.

Samek, T. (2007). Librarianship and human rights: A twenty-first century guide. Chandos Publishing (Oxford) Limited.

Streefkerk, R. (2020). APA 7th edition: The most notable changes. https://www.scribbr.com/apastyle/apa-seventh-edition-changes/

Srinuan, C. ve Bohlin, E. (2011, 18-21 Eylül). Understanding the digital divide: A literature survey and ways forward. 22nd European Regional Conference of the International Telecommunications Society (ITS2011), Budapest. Innovative ICT Applications-Emerging Regulatory, Economic and Policy Issues.

Toffler, A. (1981). The third wave. Bantam Books.

Virilio, P. (2003). Enformasyon bombası (K. Şahin, Çev.). Metis Yayınları. 